\title{
BMJ Open Undernutrition and associated factors in orphan children aged 6-59 months in Gambella Southwest, Ethiopia: A community-based cross-sectional study
}

\author{
Solomon Feleke, ${ }^{1}$ Gudina Egata, ${ }^{2}$ Firehiwot Mesfin, ${ }^{3}$ Gizachew Yilak, ${ }^{4}$ \\ Abebaw Molla (1) ${ }^{5}$
}

To cite: Feleke S, Egata G, Mesfin F, et al. Undernutrition and associated factors in orphan children aged 6-59 months in Gambella Southwest, Ethiopia: A community-based crosssectional study. BMJ Open 2021;11:e045892. doi:10.1136/ bmjopen-2020-045892

- Prepublication history for this paper is available online. To view these files, please visit the journal online (http://dx.doi org/10.1136/bmjopen-2020045892).

Received 15 0ctober 2020 Accepted 27 June 2021

\section{Check for updates}

(c) Author(s) (or their employer(s)) 2021. Re-use permitted under CC BY-NC. No commercial re-use. See rights and permissions. Published by BMJ.

${ }^{1}$ Mekidm Ethiopia Nationa Association, Addis Ababa, Ethiopia

${ }^{2}$ School of Public Health, College of Health Sciences, Addis Ababa University, Addis Ababa, Ethiopia ${ }^{3}$ Department of Nursing, School of Nursing and Midwifery, College of Health and Medical Sciences, Haramaya University, Harar, Ethiopia

${ }^{4}$ Department of Nursing, College of Health Sciences, Woldia University, Woldia, Ethiopia ${ }^{5}$ Department of Nutrition, School of Public Health, College of Health Sciences, Mizan-Tepi University, Mizan-Teferi, Ethiopia

Correspondence to

Abebaw Molla;

abebawtsehay1@gmail.com

\section{ABSTRACT}

Objective The study aimed to assess the prevalence of stunting, wasting, underweight and associated factors in orphaned children under 5 years old.

Design A cross-sectional study.

Setting Gambella City, Ethiopia.

Participants A sample of 419 under 5 orphaned children included in the study. Eligible households with orphans had selected using a systematic random sampling method. The lottery method was used when more than one eligible study participants live in the household. An OR with $95 \% \mathrm{Cl}$ was performed to measure the strength of association between each dependent variable and independent variables. Variables with $p<0.05$ were declared statistically significant.

Primary outcome The main outcome of this study was the prevalence of undernutrition among orphaned under 5 and its associated factors.

Results Prevalence of stunting, wasting and underweight in orphan children under 5 were $12.2 \%, 37.8 \%$ and $21.7 \%$, respectively. The prevalnce of wasting peaks among age group of 36-47 months (42.5\%), whereas underweight peaks in 48-59 months (27.7\%). Food insecurity, wealth index, family size, vitamin A supplementation, diarrhoea, fever 2 weeks before the survey, children under 5 and parents' death were associated with undernutrition. Conclusion The prevalence of stunting, wasting and underweight among orphan children under 5 was significantly high. Multisectoral collaborative efforts towards access to health services, improving incomegenerating activities, micronutrient supplementation and social support and protection targeting orphan and vulnerable populations have to be built up.

\section{INTRODUCTION}

Undernutrition in children under 5 remains a top public health problem of developing countries. ${ }^{1}$ Undernutrition results from inadequate intake of micro and macronutrients and is classified as stunting, wasting, underweight and micronutrient deficiencies. ${ }^{23}$ In 2018, nearly 149 million under 5 children were stunted, ${ }^{3}$ and over three-fourth of under 5 deaths were caused by undernutrition. ${ }^{4}$
Strength and limitation of this study

- The study conducted at the community level, and the information can be generalised to the population.

- This study used a multivariate logistic regression analysis to control all potential confounders.

- This study had anthropometric measurement error, social desirability bias and recall bias.

- The problem of reverse causality is an important limitation of this study.

- Besides, ORs were likely to be overestimated because of the high prevalence of outcome of interests.

The UNICEF and global partners defined an orphan as a child aged under 18 years and lost either a parent. ${ }^{5}$ In 2015, nearly 140 million orphan children lived globally, and most orphans live in Asia and Africa. Of the total orphan children, 61 million and 52 million orphans live in Asia and Africa, respectively. ${ }^{5}$ The burden of orphans is highest in sub-Saharan Africa as compared with other regions of the world. Twelve per cent of sub-Saharan African children are orphans. ${ }^{6}$ In Ethiopia, there are 5 million orphan children, of which 1.5 million are because of HIV/AIDS. ${ }^{7}$ In Ethiopia, prevalence of stunting, underweight and wasting among the general population was $38 \%, 24 \%$ and $10 \%$, respectively. ${ }^{8}$ Study findings in northwest Ethiopia showed that the prevalence of stunting, wasting and underweight among orphan children was $45.7 \%, 27.8 \%$ and $9.9 \%$, respectively. ${ }^{9}$ Likewise, a study done in southern Ethiopia indicated that the prevalence of wasting among orphan children was $11.1 \% .{ }^{10}$ In the general population, malnutrition arises from complex and interlinked factors classified as basic, underlying and immediate causes. ${ }^{11}$ Natural disasters, war, conflict, diseases, poor health services, lack of health infrastructure, poverty and migration 
are causes of orphanhood. ${ }^{12}$ In Ethiopia, poverty, HIV/ AIDS, war, food insecurity, conflict, natural disaster and malaria are significant causes of orphanhood. ${ }^{9}$ Orphan children have a more significant burden of malnutrition, deprived of adequate access to health services, education, protection, psychological support and emotional attachment, and they are more exposed to ill-treatment, abuse, engagement in unsafe work and human trafficking. ${ }^{6} 1213$ Orphan children also have poor health, reduced cognitive and emotional development, decreased physical growth and a high school dropout rate compared with nonorphan children. ${ }^{13-15}$ Identifying and addressing macro and micronutrient deficiency in resource-poor settings essential to break the intergenerational cycle of malnutrition, improve population health, ensure optimum physical growth and mental development. However, previous research focuses on the nutritional status of the general population and associated factors, ${ }^{16-21}$ and information on the prevalence of undernutrition and its predictors among orphan children in Ethiopia is limited. Hence, the main objective of this study was to assess the prevalence of undernutrition and associated factors, and the evidence produced from the study will help policymakers, government and nongovernmental organisations to design context-specific interventions.

\section{METHODS AND MATERIALS}

\section{Study design, period and setting}

A community-based cross-sectional study design was conducted from January to March 2018 in Gambella Town, Gambella Peoples Region, Southwest Ethiopia. Gambella town is the Gambella region's capital city, which is located $766 \mathrm{~km}$ away from the southwest of Addis Ababa, Ethiopia's capital. According to the central statistical agency, the town has 207000 men and 189000 women. ${ }^{22}$

\section{Study participants and sampling procedure}

According to the Gambella city women, children and youth office report, there were a total of 7521 orphan children 6-59 months living in the city. The study population was all orphan children aged 6-59 months living in Gambella town. Orphan children aged 6-59 months paired with caregivers or guardians living for at least 6 months in Gambella town included in the study. The town has five kebeles, and the sample size was allocated proportionally to each kebele. A systematic sampling technique was used to select study participants, and women, children and youth office registration books were used as the sampling frame. When two or more orphans were lived in the household, one orphan was selected using the lottery method. Orphan or caregiver who was sick during data collection was excluded from the study. The minimum sample size of the study was calculated using single population proportion formula with the following assumptions: prevalence of stunting (45.7\%), underweight (27.8\%), wasting $(9.9 \%),{ }^{9} 95 \%$ of CI, $5 \%$ precision and $10 \%$ nonresponse rate. Finally, a large sample size (419) of orphans were taken for the study.

\section{Data collection methods and tools}

Data were collected through the home to home visit, and each caregiver or guardian had provided informed written consent. Data on sociodemographic variables were collected from the guardian or caregiver using pretested and structured interviewer-administered questionnaires adapted from previous studies. ${ }^{9} 18192324$ The age of the children was taken from the caregiver's verbal report. Anthropometric measurement of height/length and weight of children was measured to assess the nutritional status of the children. Length of the children aged 6-23 months was measured to the nearest $0.1 \mathrm{~cm}$ by UNICEF length board with movable headpiece, while a child was in the recumbent position and child's head, shoulder, back, buttock and heel were against length board. The height of children aged 24-59 months was measured to the nearest $0.1 \mathrm{~cm}$ using a wooden board at a standing position, barefooted and bareheaded. Weight was measured using UNICEF salter scale to the nearest $0.1 \mathrm{Kg}$ and a $2 \mathrm{~kg}$ standard iron weight was used to calibrate the weight scale. Household food security was assessed using Household Food Insecurity Access Scale validated tool developed by Food and Nutrition Technical Assistance. The tool has nine occurrence questions followed by nine frequency of occurrence questions that measure the severity of household food insecurity in the past 4 weeks. ${ }^{25}$ Wealth index data were collected using information from ownerships available assets; animal, agricultural land, radio, television, refrigerator, car, bicycle, cart, gold, sofa, source of water, availability of electric city, type of toilet and household characteristics; type of wall, floor and ceiling. ${ }^{8}$ This study was conducted following the World Medical Association Declaration of Helsinki's ethical principles for human subject research. ${ }^{26}$

\section{Variables of the study}

Dependent variables

The dependent variable is malnutrition, described in terms of stunting, wasting and underweight status.

\section{Independent variables}

In this study, independent variables considered for regression analysis were selected from previous similar studies. ${ }^{9} 24$ 27-30 The variables such as age and sex of a child, number of children under 5 , family size, educational status of caregiver, occupational status of caregiver, marital status of the caregiver, caregiver relationship, age of caregiver, orphan status, socioeconomic status, food security, taking vitamin A supplementation, vaccination, source of water, availability of latrine, waste disposal system, handwashing after toilet, a child with a history of fever, cough or diarrhoea 2 weeks before the survey were considered independent variables. In this study, vaccination a child aged 9-12 months who received all essential childhood vaccines; Bacillus Calmette-Guerin 


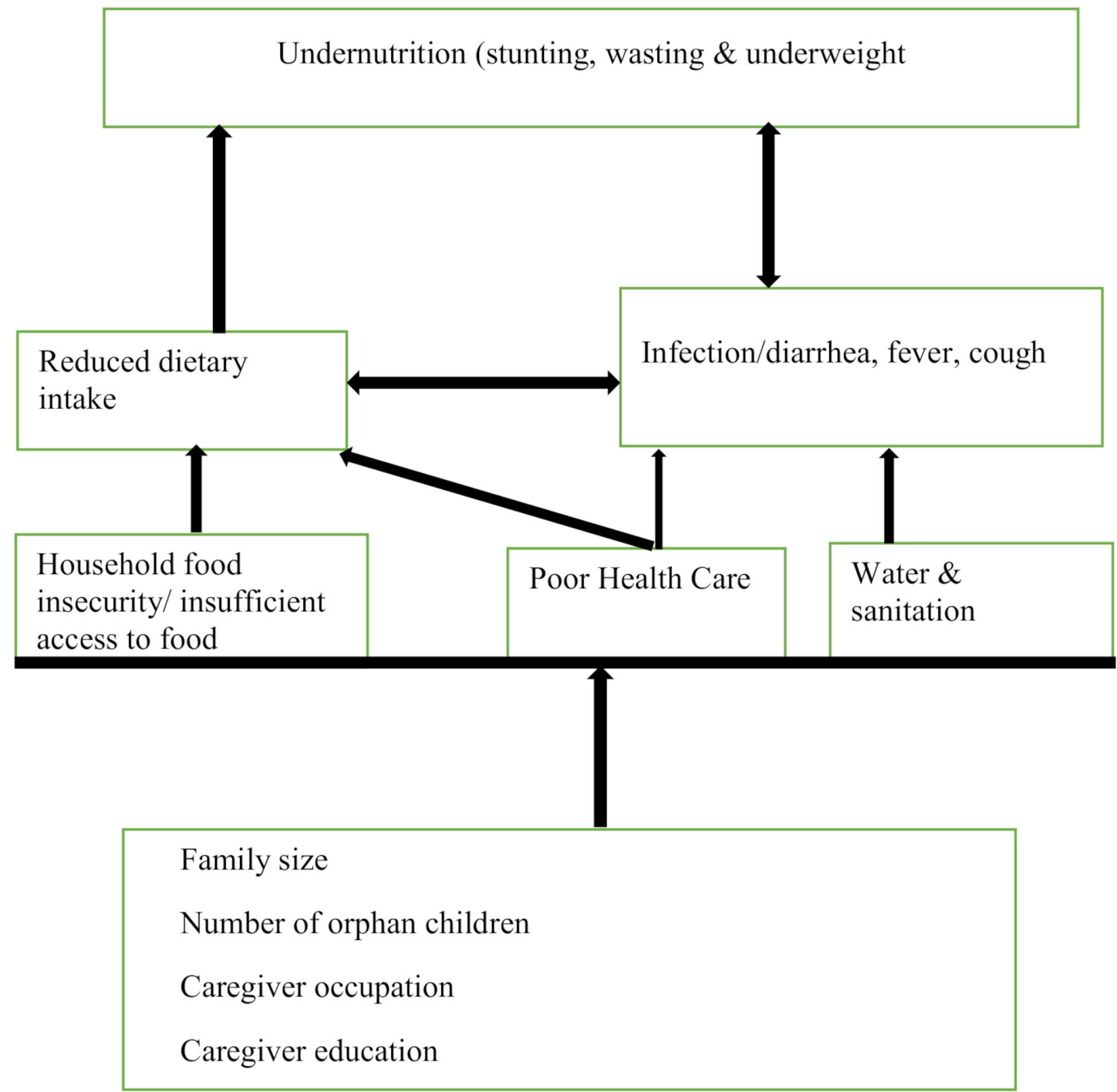

Figure 1 Theoretical framework for investigating the association between orphan children under 5 and malnutrition in Gambella Southwest Ethiopia, 2018.

(BCG), polio, pentavalent (Diphtheria, tetanus, pertussis, Haemophilus influenza, and hepatitis $B$ vaccine) and measles or child aged less than 9 months who received essential childhood vaccines except measles.

\section{Theoretical, conceptual model}

The theoretical, conceptual framework of how orphan children lead to malnutrition is developed from the UNICE conceptual framework of malnutrition in the general population and other similar works of the literature. The theoretical framework hypothesised that the factors associated with orphan children under 5 malnutrition classified as basic, underlying and proximal factors. As indicated in figure 1, the distal factors; socio-economic status, death of a parent, family size, educational and occupational status of caregiver number of under 5, may lead to intermediate factors; insufficient food, inadequate healthcare, lack of safe drinking water and inadequate sanitation, which in turn result in reduced dietary intake and infections; fever, diarrhoea and cough lead to undernutrition (stunting, wasting and underweight).

\section{Measurement}

\section{Stunting}

Length/height for age $<-2 \mathrm{SD}$ of the WHO child growth standard median. ${ }^{31}$

Wasting

Weight for height $<-2$ SD of the WHO child growth standards median. ${ }^{31}$

\section{Underweight}

Weight for age $<-2$ SD of the WHO child growth standards median. ${ }^{31}$

\section{Food secure}

When the household had no experience of food insecurity conditions or only experience rarely worry in the past 4 weeks. $^{32}$

\section{Food insecure}

Household experiences at least mild food insecurity condition in the past 4 weeks. ${ }^{32}$ 


\section{Wealth index}

Wealth index is a proxy indicator of study participant living standards derived from owners' available assets and household characteristics. Wealth index was constructed using principal component analysis (PCA) and wealth score was classified into terciles; poor, medium and rich wealth index. ${ }^{8}$

\section{Data quality control}

Initially, the data collection tool prepared in English was translated into the local language and translated back to English for consistency. Before commencement of actual data collection, a pretest had done on $5 \%$ of the study sample, and data collectors and supervisors were trained for 2 days. Then, two independent data clerks entered the data to check the consistency.

\section{Statistical analysis}

First, data were checked for completeness and accuracy. Then, data were coded and entered into Epi Data V.3.1 software and exported to SPSS V.22 software for analysis. PCA was used to construct a household wealth index, and the household wealth score was classified into terciles; poor, medium and rich. Nutritional indices; height for age $\mathrm{Z}$ score, height for weight $\mathrm{Z}$ score and weight for age $\mathrm{Z}$ score were determined based on the WHO 2006 child growth standards. ${ }^{31}$ The WHO Anthros 2005 Software V.3.2.2 was used to calculate $\mathrm{SD}$ scores or $\mathrm{Z}$ score, and children were classified into stunted (HAZ $<-2$ SD Z scores), underweight (WAZ $<-2$ SD Z scores) and wasted (WHZ <-2 SD Z scores).

Multicollinearity between predictor variables was checked using $\mathrm{SE}$, and the variable with $\mathrm{SE} \geq 0.2$ was dropped from the analysis. Bivariable logistic regression analysis was used to see the association between each predictor with outcomes of interest (stunting, wasting and underweight). Variable with a $\mathrm{p}$ value $<0.25$ during bivariable analysis was considered a candidate for multivariate logistic regression analysis to control all possible confounders and identify stunting, wasting and underweight predictors. Final regression models were built using backward elimination of variables with backward likelihood ratio 0.1 probability of removal and the variable with $\mathrm{p}$ value $\leq 0.05$ retained in the final model. The goodness of fit for the final regression models was checked by the Hosmer-Lemeshow goodness of fit test with a $\mathrm{p}$ value of $\geq 0.05$ considered a good fit. Final models of HosmerLemeshow goodness of fit test of stunting, wasting and underweight were $0.56,0.11$ and 0.7 , respectively. The adjusted OR and 95\% CIs were used to measure the strength of association, and statistical significance was declared at $\mathrm{p}$ value $<0.05$.

\section{Patient and public involvement}

Patients and the public were not involved in the design, conduct of the study, choice of outcome measures and recruitment of the study. Also, patients and the public were not involved in selecting reporting methods and disseminating the study results.

\section{RESULTS}

\section{Characteristics of study participants}

A total of 410 orphans-caregiver paired were participated in the study, making a response rate of $97.8 \%$, and more than half, 219 (53.4), were female orphans. The mean $( \pm \mathrm{SD})$ age of children was $32( \pm 15)$ months, and the majority, 226 (55.1), of orphans were in the age group of 24-59 months. The majority of 346 (84.4\%) orphans was double orphans, and nearly three-fourth $299(73 \%)$ of orphan children lived with guardians or relatives. The majority, $363(88.5 \%)$ orphan children, lived with a family size of four and above. Slightly more than one-third, 136 $(33.2 \%)$ orphans, had a history of cough before the survey, whereas about $144(35.1 \%)$ of orphan children had experienced a history of cough and fever 2 weeks before the survey. About 209 (51\%) of the respondents had formal education (table 1 ).

\section{Water, sanitation and hygiene characteristics}

The majority 350 ( $85 \%$ ) households had access to a piped water, and about $375(91.5 \%)$ households had latrines, of which $238(58 \%)$ households had pit latrine. Furthermore, $315(77 \%)$ of the household had handwashing facilities. More than two-third, 282 (69\%), were used pits as domestic waste disposal systems (table 2).

\section{Prevalence of undernutrition}

The prevalence of stunting, wasting and underweight was $12.2 \%$ (95\% CI 8.5 to 14.4 ), $37.8 \%$ (95\% CI 33.4 to 42.2 ) and $21.7 \%(95 \%$ CI 18.0 to 25.9$)$, respectively. Of which $4.9 \%(95 \%$ CI 2.5 to 7.3$), 5.1 \%$ (95\% CI 2.9 to 7.3$)$ and $3.9 \%$ (95\% CI 2.2 to 5.6$)$ was severely stunted, wasted and underweight, respectively. More male orphans were stunted than females $14.7 \%(95 \%$ CI 9.4 to 19.9$)$ and $8.2 \%$ (95\% CI 4.6 to 12.3$)$, respectively, whereas wasting was slightly higher among female orphans than male orphans, $39.3 \%$ (95\% CI 32.9 to 45.1 ) versus $36.1 \%$ (95\% CI 28.3 to 42.9 ). Prevalence of wasting and underweight was higher among orphan between age group 36-47 months, $42.5 \%$ (95\% CI 31.8 to 52.9$), 27.7 \%$ (95\% CI 15.3 to 34.1 ), respectively (figure 2 ).

\section{Factors associated with stunting, wasting and underweight}

During bivariable logistic regression analysis, educational status, food insecurity, family size, number of under 5, wealth index, occupation, vitamin A supplementation and orphan status were associated with stunting and candidate for multivariable analysis. After adjustment, orphan status, family size, food insecurity, wealth index, number of children under 5 and vitamin A supplementation were associated with stunting (table 3).

On the other hand, family size, food insecurity, wealth index, vitamin A supplementation, fever and history of diarrhoea had an association with wasting. However, in 
Table 1 Sociodemographic characteristics of orphan children aged 6-59 months caregiver paired in Gambella Town, Southwest, Ethiopia, $2018(n=410)$

\begin{tabular}{lc}
\hline Variables & Frequency $\mathbf{n}(\%)$ \\
\hline Child age (in months) & \\
$6-11$ & $86(21.0)$ \\
$12-23$ & $98(23.9)$ \\
$24-35$ & $103(25.1)$ \\
$36-47$ & $85(20.7)$ \\
$48-59$ & $38(9.3)$ \\
$6-23$ & $184(44.9)$ \\
$24-59$ & $226(55.1)$ \\
Child sex & \\
Male & $191(46.6)$ \\
Female & $219(53.4)$ \\
\hline
\end{tabular}

Number of under 5 in the household

$\begin{array}{ll}<2 & 290(70.7) \\ \geq 2 & 120(29.3)\end{array}$

Family size

$\begin{array}{lr}\leq 3 & 47(11.5) \\ 4-6 & 256(62.4) \\ \geq 7 & 107(26.1)\end{array}$

\section{Respondent religion}

\begin{tabular}{|rr} 
Orthodox & $63(15.1)$ \\
\hline Muslim & $58(14.1)$ \\
\hline Protestant & $50(12.1)$ \\
\hline Catholic & $239(58.3)$ \\
\hline
\end{tabular}

Ethnicity

$\begin{array}{lc}\text { Nuewer } & 173(42.2) \\ \text { Agnwake } & 91(22.2) \\ \text { Oromo } & 68(16.6) \\ \text { Tiger } & 24(6.1) \\ \text { Amhara } & 54(12.9)\end{array}$

Sex of respondent

$\begin{array}{lr}\text { Male } & 92(22.4) \\ \text { Female } & 318(77.6) \\ \text { Educational status of the caregiver } & \\ \text { No formal education } & 201(49.0) \\ \text { Primary education } & 81(19.8) \\ \text { Secondary and above } & 128(31.2) \\ \text { Occupation of respondent } & \\ \text { Housewife } & 112(27.3) \\ \text { Employed } & 111(27.1) \\ \text { Merchant } & 144(35.1) \\ \text { Daily worker } & 43(10.5) \\ \text { Marital status of the respondent } & 61(14.9) \\ \text { Single } & \text { Continued }\end{array}$

\begin{tabular}{|c|c|}
\hline Variables & Frequency n (\%) \\
\hline Married & $225(54.9)$ \\
\hline Widowed & 89 (21.9) \\
\hline Divorced & $35(8.5)$ \\
\hline \multicolumn{2}{|c|}{ Caregiver/respondent relationship } \\
\hline Parent & $59(14.4)$ \\
\hline Grandparent & $26(6.3)$ \\
\hline Guardian/relatives & $299(73.0)$ \\
\hline Brother/sister & $26(6.3)$ \\
\hline \multicolumn{2}{|l|}{ Age of respondent } \\
\hline$\leq 30$ & $66(16.1)$ \\
\hline $30-40$ & $125(30.5)$ \\
\hline $41-50$ & $99(24.1)$ \\
\hline$\geq 50$ & $120(29.3)$ \\
\hline \multicolumn{2}{|c|}{ One biological parent live } \\
\hline Yes & $64(14.6)$ \\
\hline No & $346(84.4)$ \\
\hline \multicolumn{2}{|l|}{ Socioeconomic status } \\
\hline Poor & $195(47.6)$ \\
\hline Medium & $105(25.6)$ \\
\hline Rich & $110(26.8)$ \\
\hline \multicolumn{2}{|c|}{ Household food security status } \\
\hline Food secure & 307 (74.9) \\
\hline Food insecure & $103(25.1)$ \\
\hline \multicolumn{2}{|c|}{$\begin{array}{l}\text { A child with a history of fever } 2 \text { weeks } \\
\text { before the survey }\end{array}$} \\
\hline Yes & $136(33.2)$ \\
\hline No & $274(66.8)$ \\
\hline
\end{tabular}

A child with a history of diarrhoea 2 weeks before the survey

$\begin{array}{lr}\text { Yes } & 196(47.8) \\ \text { No } & 214(52.2) \\ \text { A child taking vitamin supplementation } & \\ \text { Yes } & 298(72.7) \\ \text { No } & 112(27.3) \\ \text { Child received vaccination } & \\ \text { Yes } & 54(13.2) \\ \text { No } & 230(56.1) \\ \text { Do not know } & 126(30.7)\end{array}$

A child has a history of cough 2 weeks before the survey.

\begin{tabular}{ll} 
Yes & $144(35.1)$ \\
No & $266(64.9)$ \\
\hline
\end{tabular}

multivariable logistic regression analysis, only wealth index, fever and vitamin A supplement status were significantly associated with wasting (table 4). In bivariable analysis, children under 5 , family size, food security, wealth 
Table 2 Water, sanitation and hygiene characteristics of a caregiver of orphan children aged 6-59 months in Gambella Town, Southwest Ethiopia, $2018(n=410)$

\begin{tabular}{|c|c|}
\hline Variables & Frequency n (\%) \\
\hline \multicolumn{2}{|l|}{ Source of water } \\
\hline Pipe & $279(68.0)$ \\
\hline Public stand & $131(32.0)$ \\
\hline \multicolumn{2}{|l|}{ Method of water storage } \\
\hline Pot & 34 (8.3) \\
\hline Jerrican/plastic container & $376(91.7)$ \\
\hline \multicolumn{2}{|l|}{ Hand washing after toilet } \\
\hline Yes & $315(76.8)$ \\
\hline No & 95 (23.2) \\
\hline \multicolumn{2}{|l|}{ Latrine availability } \\
\hline Yes & $375(91.5)$ \\
\hline No & $35(8.5)$ \\
\hline \multicolumn{2}{|l|}{ Type of latrine } \\
\hline Private pit & $123(30.0)$ \\
\hline Pit & $238(58.0)$ \\
\hline Water carriage & 49 (12.0) \\
\hline \multicolumn{2}{|l|}{ Waste disposal system } \\
\hline Pit & $282(68.8)$ \\
\hline Open & $118(28.8)$ \\
\hline Municipality & $10(2.4)$ \\
\hline \multicolumn{2}{|l|}{ Separated kitchen } \\
\hline Yes & $288(70)$ \\
\hline No & $122(30)$ \\
\hline
\end{tabular}

index, vitamin A supplementation, diarrhoea and fever were associated with underweight. However, in multivariable analysis, family size, wealth index, vitamin A supplementation and diarrhoea had a significant association (table 5).

\section{DISCUSSION}

The present study assessed the prevalence of stunting, wasting, underweight and associated factors among the most vulnerable population group. The prevalence of stunting, wasting and underweight among orphaned children was $12.2 \%, 37.8 \%$ and $21.7 \%$, respectively. However, the study finding should be interpreted with caution because the study conducted in the Gambella region capital city, and orphans who reside in the city may have better care and nutritional support than semiurban and rural setting residents. Also, several nongovernmental organisations work on humanitarian activities in the study area, which may also influence the study findings.

In this study, the prevalence of stunting was consistent with the study conducted in African countries such as Malawi $\left(9.1 \%\right.$ ) and Nigeria (12.4\%). ${ }^{29}{ }^{33}$ However, the present finding is lower than the study done in Asian countries such as Palestine (17.6\%), India (18.6\%), China (20\%) and Pakistan (21\%), ${ }^{34-37}$ respectively. Also, the finding is lower compared with the study conducted in African countries; Zimbabwe (29\%), Malawi (30.4\%), Ghana $(17.9 \%)$ and South Africa $(18 \%),{ }^{27-29} 38$ respectively, and Ethiopia was in the range $(35.1 \%-45.7 \%))^{924}$ The possible reason for variation may be differences in geographical, sociocultural, nutritional support, and study period variation could contribute to the variation.

Figure 2 Prevalence of undernutrition by age category among orphaned children 6-59 months in Gambella Town, Southwest Ethiopia, 2018.

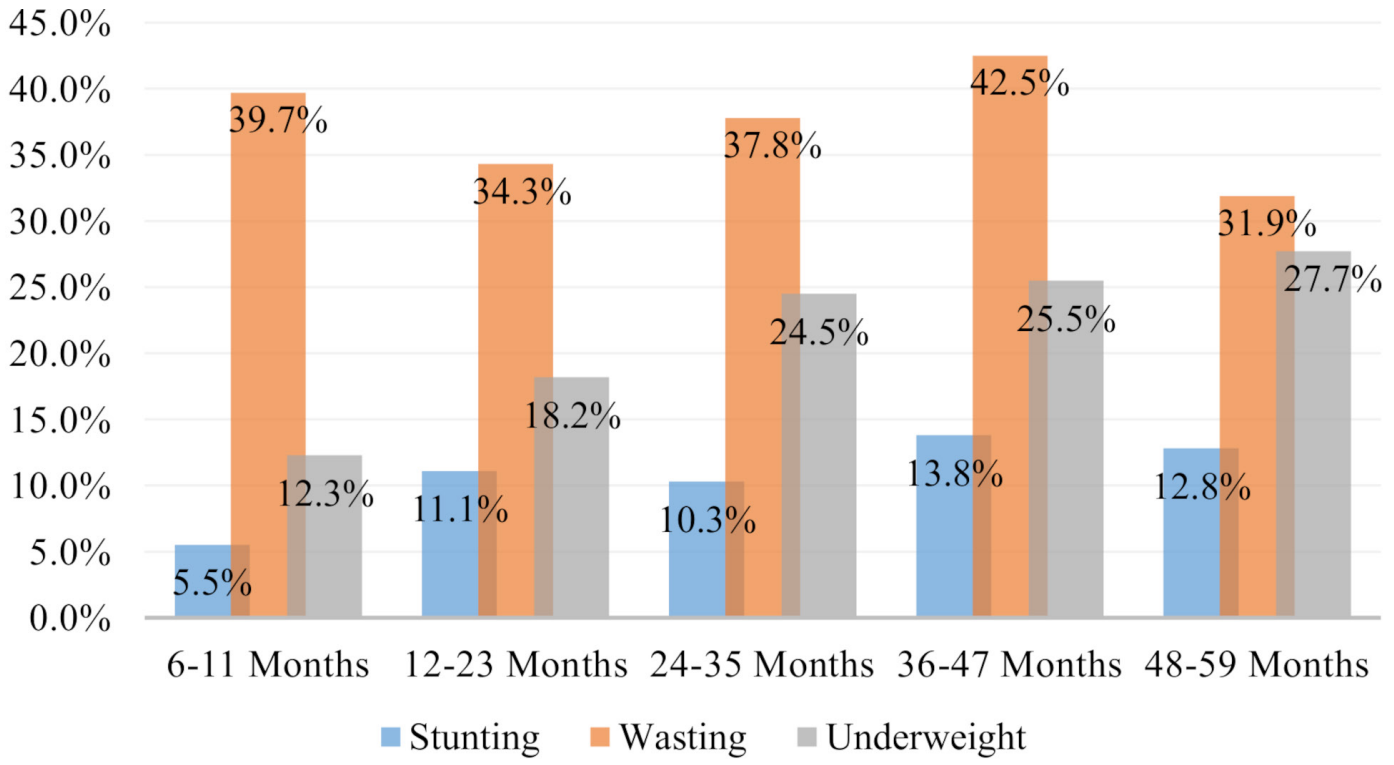


Table 3 Factors associated with stunting among orphaned children aged 6-59 months in Gambella Town, Southwest, Ethiopia, $2018(n=410)$

\begin{tabular}{|c|c|c|c|c|}
\hline Variables & Stunted N (\%) & Normal N (\%) & COR $(95 \% \mathrm{Cl})$ & AOR $(95 \% \mathrm{Cl})$ \\
\hline No formal education & $30(14.9)$ & $171(85.1)$ & 3.6 (1.4 to 8.8$)$ & $2.4(0.8$ to 7.2$)$ \\
\hline$\geq$ Secondary & $6(4.7)$ & $122(95.3)$ & Reference & Reference \\
\hline \multicolumn{5}{|l|}{ HHFI status } \\
\hline Insecure & $79(76.7)$ & 24 (23.3) & 3.9 (2.1 to 7.4$)$ & $2.7(1.3 \text { to } 5.8)^{\star}$ \\
\hline \multicolumn{5}{|l|}{ Family size } \\
\hline$<4$ & $10(5.2)$ & $184(94.8)$ & Reference & Reference \\
\hline$\geq 4$ & $36(16.7)$ & $180(83.3)$ & 3.2 (1.6 to 6.5$)$ & $3.0(1.3 \text { to } 6.9)^{\star}$ \\
\hline \multicolumn{5}{|l|}{ Wealth index } \\
\hline Poor & 35 (17.9) & $160(82.1)$ & 11.8 (2.8 to 50.1$)$ & $10.4(2.2 \text { to } 48.3)^{\star}$ \\
\hline Medium & $9(8.6)$ & $96(91.4)$ & 5.0 (1.0 to 24.0 ) & 4.0 (0.8 to 21.2$)$ \\
\hline Rich & $2(1.8)$ & 108 (98.2) & Reference & Reference \\
\hline \multicolumn{5}{|l|}{ Caregiver occupation } \\
\hline Housewife & $19(16.8)$ & $94(83.2)$ & 0.7 (0.3 to 1.8$)$ & $1.3(0.5$ to 3.0$)$ \\
\hline Employed & $8(7.2)$ & $103(91.1)$ & 0.3 (0.1 to 0.8$)$ & 0.9 (0.3 to 2.8$)$ \\
\hline Merchant & $11(7.6)$ & $133(92.4)$ & 0.3 (0.1 to 0.8$)$ & $0.4(0.1$ to 1.5$)$ \\
\hline Daily worker & 9 (20.9) & $34(79.1)$ & Reference & Reference \\
\hline Double & $51(14.8)$ & 295 (85.2) & Reference & Reference \\
\hline
\end{tabular}

${ }^{*} p$-value $<0.05$.

AOR, adjusted OR; COR, crude OR; HHFI, Household Food Insecurity.

In general, the prevalence of stunting is greater than underweight and wasting and underweight higher than wasting in the general population. However, in our study, wasting found the most critical finding markedly higher than stunting and underweight. Wasting indicator is a consequence of transitory insufficient food intake and or high incidence of infectious disease, leading to the weakened immune system and increased risk of susceptibility to infectious diseases and death. ${ }^{39}$ Hence, the highest burden of acute malnutrition in the current study could be associated with a higher incidence of epidemic diseases in the region, such as acute respiratory infection, malaria, measles, fever and acute watery diarrhoea. Furthermore, our study finding is consistent with previous shreds of evidence. The prevalence of wasting in the Gambella region increases since 2000, and stunting shows a decline, and the burden of wasting is highest next to the Somali and Afar regions in the country. $^{40}$

In this study, the prevalence of acute malnutrition is consistent with a study in Bangladesh (33\%), Punjab and West Bengal, India $(38.5 \%, 35.1 \%),{ }^{41-43}$ respectively. However, the finding of the present study is considerably higher compared with study done in eastern India $(18 \%)$, Palestine $(8.8 \%)$, Ghana $(5.3 \%)$, Zimbabwe $(5 \%)$, Malawi $(12.5 \%)$ and China $(3.07 \%) .{ }^{27-30} 3436$ The finding also higher than the study done in Gondar city $(7.5 \%)$, Dilla town $(9.9 \%)$, Hawassa city $(11 \%)^{91024}$ and the national prevalence of Ethiopia $(10 \%) .{ }^{8}$ On the other hand, the finding is lower as compared with the study from northern India $(62 \%)$, Nigeria $(47.5 \%)$ and Kenya $(47 \%) .{ }^{44-46}$ The dissimilarities may be due to the nutrition support system, 
Table 4 Factors associated with wasting among OC aged 6-59 months in Gambella Town, Southwest, Ethiopia, $2018(\mathrm{n}=410)$

\begin{tabular}{|c|c|c|c|c|}
\hline Variables category & Wasted N (\%) & Normal (\%) & COR $(95 \% \mathrm{Cl})$ & AOR $(95 \% \mathrm{Cl})$ \\
\hline \multicolumn{5}{|l|}{ Family size } \\
\hline$<4$ & $63(32.5)$ & $131(67.5)$ & Reference & Reference \\
\hline$\geq 4$ & $92(42.6)$ & $124(57.4)$ & $1.5(1.0,2.3)$ & $1.5(0.9,2.2)$ \\
\hline \multicolumn{5}{|l|}{ Diarrhoea } \\
\hline Yes & $87(44.4)$ & $109(55.6)$ & $1.7(1.1,2.6)$ & $1.4(0.9,2.2)$ \\
\hline No & $68(31.8)$ & $146(68.2)$ & Reference & Reference \\
\hline \multicolumn{5}{|l|}{ Fever } \\
\hline Yes & $62(45.6)$ & $74(54.4)$ & $1.6(1.0,2.5)$ & $1.6(1.0,2.5)^{*}$ \\
\hline No & 93 (33.9) & $181(66.1)$ & Reference & Reference \\
\hline \multicolumn{5}{|l|}{ Food security } \\
\hline Food secured & $104(33.9)$ & $203(66.1)$ & Reference & Reference \\
\hline Food insecure & $51(49.5)$ & $52(50.5)$ & $1.9(1.2,3.0)$ & $1.4(0.9,2.3)$ \\
\hline \multicolumn{5}{|l|}{ Wealth index } \\
\hline Poor & $86(44.1)$ & 109 (55.9) & $2.3(1.4,3.9)$ & $2.3(1.4,3.9)^{\star}$ \\
\hline Medium & $41(39.0)$ & $64(61.0)$ & $1.9(1.0,3.3)$ & $1.9(1.0,3.4)$ \\
\hline Rich & $28(25.5)$ & $82(74.5)$ & Reference & Reference \\
\hline \multicolumn{5}{|l|}{ Taking Vitamin A } \\
\hline Yes & 101 (33.9) & $197(66.1)$ & Reference & Reference \\
\hline No & $54(48.2)$ & $58(51.8)$ & $1.8(1.16,2.8)$ & $1.5(1.0,2.3)$ * \\
\hline
\end{tabular}

AOR, adjusted OR; COR, crude OR; OC, orphan children.

access to healthcare service, population and study period differences.

In the current study, the prevalence of underweight was $21.7 \%$, and the finding is in line with study results in Zimbabwe (19\%), urban union council of Abbottabad $(21 \%)$, northeast Ethiopia $(24.8 \%)^{19} 2837$ and the national prevalence of Ethiopia $(24 \%){ }^{8}$ In contrast, the study finding is lower as compared with the study in India (31.9\%), Vietnam (27.7\%, Malawi (33.4\%), Nigeria $(45.5 \%)$ and Uganda (30\%). ${ }^{29} 30444748$ The current study result is lower compared with the study done in northwest Ethiopia (27.8\%) and northeast Ethiopia (46.1\%). ${ }^{9} 16$ On the other hand, this finding is far higher than the study done in China (7.2\%), Ghana $(7.7 \%)$, Nigeria $(14.8 \%)$, southern Ethiopia (8.9\%) and west Ethiopia $(14.5 \%) .^{2124273649}$ The possible reasons for the differences may be variations in the study setting, population, sample size, period, nutrition and healthcare support system and sociocultural variations.

Our study identified several factors associated with stunting, wasting and underweight among orphan children under 5 years. Orphan children who lived in foodinsecure households had more odds of stunting and underweight compared with the orphan children who lived in food-secure households. A similar study in Kenya established the association between food insecurity and higher odds of stunting and underweight among orphan children. ${ }^{50}$ Because orphaned children who lived in food-insecure households may not have sufficient access to an adequate, diversified and balanced diet to sustain optimum physical growth and development. Being in large family size had greater odds of stunting and underweight than orphans who lived in smaller family size. Likewise, orphans who lived with fewer children under 5 had $75 \%$ reduced odds of stunting. A similar study done in Malawi, Afar, Tigray and EDHS 2016 181929 affirmed that large family size and the number of children under 5 lived in the household were negatively associated child nutritional status. The possible reason may be that orphans who live in large family sizes and large numbers of under 5 could not access adequate food, healthcare service, psychosocial and nutritional support. An orphan who belongs to a poor wealth quintile household had greater odds of stunting, wasting and underweight. A similar study done in Bangladesh and Ethiopia declared the association between poor wealth index and undernutrition. ${ }^{51} 52$ Because inadequate resources decrease the ability to pay for essential health services, adequate and various food groups contribute to decreased health status and dietary intake, leading to infection and malnutrition.

In the present study, vitamin A supplementation status was significantly associated with stunting, wasting and underweight. Orphan children who did not receive vitamin A supplementation had more odds of stunting, wasting and underweight compared with an orphan who received vitamin A supplementation. A similar study in northwest Ethiopia confirmed that the odds of stunting was higher among orphan who did not receive vitamin 
Table 5 Factors associated with underweight among orphan children aged 6-59 months in Gambella Town, Southwest, Ethiopia, $2018(n=410)$

\begin{tabular}{|c|c|c|c|c|}
\hline Variables & Underweight n (\%) & Normal n (\%) & COR $(95 \% \mathrm{Cl})$ & AOR $(95 \% \mathrm{Cl})$ \\
\hline \multicolumn{5}{|c|}{ Number of under 5 children } \\
\hline$<3$ & $52(17.9)$ & $238(82.1)$ & $0.5(0.3,0.8)$ & $0.7(0.4,1.2)$ \\
\hline \multicolumn{5}{|l|}{ Family size } \\
\hline$<4$ & $28(14.4)$ & $166(85.6)$ & Reference & Reference \\
\hline \multicolumn{5}{|l|}{ Food security } \\
\hline Food secure & $53(17.3)$ & $254(82.7)$ & Reference & Reference \\
\hline Food insecure & $36(35.0)$ & $67(65.0)$ & $2.6(1.6,4.2)$ & $2.0(1.1,3.6)^{*}$ \\
\hline \multicolumn{5}{|l|}{ Wealth index } \\
\hline \multicolumn{5}{|c|}{ Vitamin A supplement } \\
\hline Yes & $41(13.8)$ & $257(86.2)$ & Reference & Reference \\
\hline No & $48(42.9)$ & $64(57.1)$ & $4.7(2.9,7.7)$ & $4.8(2.8,8.3)^{\star}$ \\
\hline \multicolumn{5}{|l|}{ Diarrhoea } \\
\hline Yes & $57(29.1)$ & $139(70.9)$ & $2.3(1.4,3.8)$ & $1.8(1.0,3.1)^{*}$ \\
\hline No & $32(15.0)$ & $182(85.0)$ & Reference & Reference \\
\hline \multicolumn{5}{|l|}{ Fever } \\
\hline Yes & $43(31.6)$ & $93(68.4)$ & $2.3(1.4,3.7)$ & $1.7(0.9,3.0)$ \\
\hline No & $46(16.8)$ & $228(83.2)$ & Reference & Reference \\
\hline
\end{tabular}

AOR, adjusted OR; COR, crude OR.

A supplementation. ${ }^{9}$ Because vitamin A has anti-infective activities and enhances the body's innate and adaptive immune system, this, in turn, reduces infections, which contributed to the immediate cause of malnutrition. However, the finding is inconsistent with studies in southern Ethiopia. ${ }^{24}$ The disagreement may be due to differences in the study population, study period and setting. Being a single orphan had $70 \%$ reduced odds of stunting compared with double orphaned. The finding agrees with a study in southern Ethiopia, ${ }^{24}$ and this may be because orphan children living with their biological parents may get better care and support than caregivers. Orphans who had a history of diarrhoea 2 weeks before the survey had more odds of underweight than diarrheafree children. In line with our finding, a study in Nigeria, Rwanda and Ethiopia demonstrated the association between diarrhoea infection and greater odds of underweight. ${ }^{2153} 54$ Infection reduces child appetite, digestion and nutrient absorption, which leads to malnutrition.

\section{CONCLUSION}

In general, the prevalence of stunting, wasting and underweight among orphaned children was markedly public health significance. Food insecurity, wealth index, family size, vitamin A supplementation, diarrhoea, fever, number of under 5 and orphan status were significantly associated with the nutritional status of orphan children. Wide-ranging intervention strategies targeted to incomegenerating activities and healthcare access; social and nutritional support should be given priority to reduce orphan undernutrition. Overall, orphan children are more exposed to various developmental, psychosocial, behavioural, health and nutritional problems. The present study assesses the prevalence of undernutrition and identified different factors associated with undernutrition. However, due to the nature of the cross-sectional study design, it is difficult to establish a causal association between variables with poor nutritional outcomes. Hence, further research is needed to establish how orphanhood leads to poor health and nutritional outcomes, including psychosocial and development outcomes.

Acknowledgements We thank Haramaya University for giving us this opportunity. Our gratitude also goes to Gambella city health bureau, Gambella town women, youth and children office, Kebele administrator, and health extension workers giving all required information.

Contributors SF: conception and original draft writing, SF, GE, FM, GY, AM: study design, data analysis and interpretations, GE, FM, GY, AM: critically review initial draft and finalizing manuscript, AM, GY, SF: preparing manuscript. All authors reviewed and approved the final manuscript. 
Funding The authors have not declared a specific grant for this research from any funding agency in the public, commercial or not-for-profit sectors.

Competing interests None declared.

Patient and public involvement Patients and/or the public were not involved in the design, or conduct, or reporting, or dissemination plans of this research.

Patient consent for publication Not required.

Ethics approval Institutional Health Research Ethics Review Committee (IHRERC) of Haramaya University, College of Medicine and Health Sciences approved the study with reference number $\mathrm{C} / \mathrm{Ac} / \mathrm{R} / \mathrm{D} / 01 / 1162 / 18$.

Provenance and peer review Not commissioned; externally peer reviewed.

Data availability statement Data are available upon reasonable request. Data are available from the corresponding author upon request.

Open access This is an open access article distributed in accordance with the Creative Commons Attribution Non Commercial (CC BY-NC 4.0) license, which permits others to distribute, remix, adapt, build upon this work non-commercially, and license their derivative works on different terms, provided the original work is properly cited, appropriate credit is given, any changes made indicated, and the use is non-commercial. See: http://creativecommons.org/licenses/by-nc/4.0/.

ORCID iD

Abebaw Molla http://orcid.org/0000-0001-5582-6449

\section{REFERENCES}

1 Black RE, Allen LH, Bhutta ZA, et al. Maternal and child undernutrition: global and regional exposures and health consequences. Lancet 2008;371:243-60.

2 WHO. Nutrition landscape information system (NLIS) country profile indicators interpretation guide; 2010.

3 UNICEF. The State of the World's Children: Children, Food and Nutrition; 2019.

4 Liu L, Oza S, Hogan D, et al. Global, regional, and national causes of child mortality in 2000-13, with projections to inform post-2015 priorities: an updated systematic analysis. The Lancet 2015;385:430-40.

5 . UNICEF; 2017.

6 UNICEF. Africa's Orphaned Generations; 2010

7 UNICEF. Africa's orphaned generations; 2003.

8 EDHS. Ethiopia demographic and health survey. Maryland, USA The DHS program, ICF Rockville; 2016.

9 Gultie Tet al. Nutritional status and associated factors among orphan children below the age of five years in Gondar City, Ethiopia. J Food Nutr Sci 2014;2:179-84.

10 Wete AT, Zerfu TA, Anbese AT. Magnitude and associated factors of wasting among under five orphans in Dilla town, southern Ethiopia: 2018: a cross-sectional study. BMC Nutrition 2019;5:1-10.

11 UNICEF. UNICEF's Approach to Scaling Up Nutrition for Mothers and their Children; 2015.

12 Cansu N. Orphan report research INSAMER; 2020

13 UNICEF/UNAIDS. Children orphaned by AIDS front-line responses from eastern and southern Africa; 1999.

14 Lindblade KA, Odhiambo F, Rosen DH, et al. Health and nutritional status of orphans $<6$ years old cared for by relatives in western Kenya. Trop Med Int Health 2003;8:67-72.

15 Subbarao Ket al. Social Protection of Africa's Orphans and Other Vulnerable Children.

16 Fentaw R, Bogale A, Abebaw D. Prevalence of child malnutrition in agro-pastoral households in afar regional state of Ethiopia. Nutr Res Pract 2013;7:122-31.

17 Demissie S, Worku A. Magnitude and factors associated with malnutrition in children 6-59 months of age in pastoral community of Dollo Ado district, Somali region, Ethiopia. Sci J Public Health 2013;1:175-83.

18 Brhane G, Regassa N. Nutritional status of children under five years of age in Shire Indaselassie, North Ethiopia: examining the prevalence and risk factors. Kontakt 2014;16:e161-70.

19 Gebre A, Reddy PS, Mulugeta A, et al. Prevalence of malnutrition and associated factors among Under-Five children in pastoral communities of afar regional state, northeast Ethiopia: a communitybased cross-sectional study. J Nutr Metab 2019;2019:9187609.

20 Endris N, Asefa H, Dube L. Prevalence of malnutrition and associated factors among children in rural Ethiopia. Biomed Res Int 2017;2017:6587853.
21 Amare D, Negesse A, Tsegaye B, et al. Prevalence of undernutrition and its associated factors among children below five years of age in Bure town, West Gojjam zone, Amhara national regional state, Northwest Ethiopia. Adv Public Health 2016;2016:1-8.

22 CSA. The DHS program. Maryland, USA ICF Rockville; 2008.

23 Braitstein P, Ayaya S, Nyandiko WM, et al. Nutritional status of orphaned and separated children and adolescents living in community and institutional environments in uasin gishu County, Kenya. PLoS One 2013;8:e70054.

24 Bisrat Get al. Assessment of the nutritional status and associated factors of orphans and vulnerable preschool children on care and support from Non-governmental organizations in Hawassa town, southern Ethiopia. Glob J Med Res 2017;16:1-41 https://medicalr esearchjournal.org/index.php/GJMR/article/view/1256

25 Coates Jet al. Household food insecurity access scale (HFIAS) for measurement of food access: indicator guide version 2007;3.

26 World Medical Association. WMA Declaration of Helsinki - ethical principles for medical research involving human subjects; 1964.

27 Ali Z, Abu N, Ankamah IA, et al. Nutritional status and dietary diversity of orphan and non - orphan children under five years: a comparative study in the Brong Ahafo region of Ghana. BMC Nutr 2018;4:1-8.

28 Watts H, Gregson S, Saito S, et al. Poorer health and nutritional outcomes in orphans and vulnerable young children not explained by greater exposure to extreme poverty in Zimbabwe. Trop Med Int Health 2007;12:584-93.

29 Panpanich R, Brabin B, Gonani A, et al. Are orphans at increased risk of malnutrition in Malawi? Ann Trop Paediatr 1999;19:279-85.

30 Routray Set al. Growth and development among children living in orphanages of Odisha, an eastern Indian state. The reason 2015;110:p. 75.3.

31 WHO. Who child growth standards 2006

32 Coates Eet al. Household food insecurity access scale (HFIAS) for measurement of food access: indicator guide 2006.

33 Ozor Met al. The prevalence of under nutrition among under five year children in Ekpoma, Edo-Nigeria. Int $\mathrm{J}$ Commun Res 2014;3:34-8.

34 Al-Adili N, Shaheen M, Bergstrom S, et al. Survival, family conditions and nutritional status of motherless orphans in the West bank, Palestine. Scand J Public Health 2008;36:292-7.

35 Kamath SM, Venkatappa KG, Sparshadeep EM. Impact of nutritional status on cognition in institutionalized orphans: a pilot study. J Clin Diagn Res 2017;11:CC01.

36 Zhang J, Shi J, Himes JH, et al. Undernutrition status of children under 5 years in Chinese rural areas - data from the National Rural Children Growth Standard Survey, 2006. Asia Pac J Clin Nutr 2011;20:584-92.

37 Lodhi HSet al. Assessment of the nutritional status of 1-5-year-old children in an urban Union Council of Abbottabad. Journal of Ayub Medical College Abbottabad 2010;22:124-7.

38 Kimani-Murage EW, Norris SA, Pettifor JM, et al. Nutritional status and HIV in rural South African children. BMC Pediatr 2011;11:1-13.

39 WHO. Nutrition landscape information system (NLIS. COUNTRY PROFILE INDICATORS: Interpretation Guide, 2010.

40 UNICEF. Situation analysis of children and women: Gambella region 2019.

41 Choudhury KKet al. Gender inequality and severe malnutrition among children in a remote rural area of Bangladesh. Journal of Health, Population and Nutrition 2000:p. 123-130.

42 Kaur G, Kang HS, Singal P, et al. Nutritional Status: Anthropometric Perspective of Pre-School Children. The Anthropologist 2005;7:99-103.

43 Biswas S, Bose K, Mukhopadhyay A. Mid-upper arm circumference based undernutrition among Bengalee children of Chapra, West Bengal, India. Iran J Pediatr 2010;20:63.

44 Steve-Edemba CL. Assessment of the feeding practices, vitamin A, iron, zinc and Anthropometrics status of Under-Five children in Orphanages of federal Capital Territory Abuja. Nigeria 2016.

45 Berkley J, Mwangi I, Griffiths K, et al. Assessment of severe malnutrition among hospitalized children in rural Kenya: comparison of weight for height and mid upper arm circumference. JAMA 2005;294): :591-7.

46 Tigga PL, Sen J, Mondal N. Association of some socio-economic and socio-demographic variables with wasting among pre-school children of North Bengal, India. Ethiop J Health Sci 2015;25:63-72.

47 Nalwoga A, Maher D, Todd J. Nutritional status of children living in a community with high HIV prevalence in rural Uganda: a cross-sectional population-based survey. Trop Med Int Health 2010;15:414-22.

48 Hien NN, Hoa NN. Under three years of age in nghean, Vietnam. Pakistan Journal of Nutrition 2009;8:p. 958-64. 
49 Akorede QJ, Abiola OM. Assessment of nutritional status of underfive children in Akure South local government, Ondo state, Nigeria. International Journal of Research and Reviews in Applied Sciences 2013;14:671-81.

50 Kimani-Murage EW, Holding PA, Fotso J-C, et al. Food security and nutritional outcomes among urban poor orphans in Nairobi, Kenya. $J$ Urban Health 2011;88 Suppl 2:p. 282-297.

51 Ma'alin Aet al. Magnitude and factors associated with malnutrition in children 6-59 months of age in Shinille Woreda, Ethiopian Somali regional state: a cross-sectional study. BMC Nutrition 2016;2:1-12.
52 Das S, Gulshan J. Different forms of malnutrition among under five children in Bangladesh: a cross sectional study on prevalence and determinants. BMC Nutrition 2017;3:1.

53 Akombi BJ, Agho KE, Merom D, et al. Multilevel analysis of factors associated with wasting and underweight among children under-five years in Nigeria. Nutrients 2017;9:44.

54 Mukabutera A, Thomson DR, Hedt-Gauthier BL, et al. Risk factors associated with underweight status in children under five: an analysis of the 2010 Rwanda demographic health survey (RDHS). BMC Nutr 2016;2:40. 